\title{
COMPARATIVE ECOSYSTEM ANALYSIS OF URBAN PONDS: IMPLICATIONS FOR SYNERGISTIC BENEFITS AND POTENTIAL TRADE-OFFS RESULTING FROM RETROFITTING OF GREEN ROOFS IN THEIR CATCHMENTS
}

\author{
VLADIMIR KRIVTSOV ${ }^{1,4}$, STEVE BIRKINSHAW $^{2}$, REBECCA YAHR $^{1} \&$ VALERIE OLIVE $^{3}$ \\ ${ }^{1}$ Royal Botanic Garden Edinburgh, Scotland, UK \\ ${ }^{2}$ Newcastle University, England, UK \\ ${ }^{3}$ SUERC, University of Glasgow, Scotland, UK \\ ${ }^{4}$ University of Edinburgh, Scotland, UK
}

\begin{abstract}
This paper provides a summary of ecological functioning, biodiversity and water chemistry of two sustainable drainage systems (SuDS) ponds, and compares the level of ecosystem services with those attainable by retrofitting green roofs (GRs) in the ponds' catchments. These study sites are characterised by relatively high diversity of habitats, including aquatic, mesic and terrestrial; the importance of the latter is highlighted using the analysis of vascular plants and calcicolous lichens. Both SuDS sites provide valuable multiple benefits related to the enhancement of local biodiversity, water quality improvement and alleviation of flood risk, and the retrofitting of GRs would further enhance flood resilience and biodiversity of the area. However, there might be potentially negative effects on the runoff water quality and hydrobiological community composition of the receiving ponds. Changes in the runoff chemistry combined with the decreases in flush rate of high-flow events would increase the risk of cyanobacterial dominance during late summer and autumn. Such trade-offs should be carefully considered in planning any practical actions. This study elucidates indirect effects by following the methodological framework of comparative ecosystem analysis, which will be of use for any research and applications considering implementation of complex nature-based solutions (NBS), including those within the context of sustainable development of blue-green cities (BGC).

Keywords: blue-green infrastructure, community structure, CTEA, hydrological modelling, indirect effects, mesofauna, newts, plankton, runoff chemistry, terrestrial flora, fungi, urban pollution.
\end{abstract}

\section{INTRODUCTION}

Sustainable drainage systems (SuDS) are an important component of modern green and blue-green infrastructure (GI/BGI), and are indispensable for sustainable urban development $[1,2]$. A well-developed GI/BGI network provides a number of important ecosystem services including, for example, flood risk reduction, water quality improvement, biodiversity enhancement, recreation capacity, among others [3-6].

Green roofs (GRs) and urban stormwater ponds are the types of SuDS whose multiple benefits have received a fair amount of attention from researchers and practitioners [7-12]. These BGI components have been increasingly used as part of nature-based solutions (NBS) both in the UK and worldwide. However, the estimation of overall benefits provided by a combination of BGI components is not straightforward, and the interactions and trade-offs between various SuDS assets remain under-investigated.

Here, we address this research gap by investigating what would happen to the ecosystem services related to hydrology, water quality and biodiversity of SuDS ponds following the retrofitting of GRs on buildings situated in the ponds' catchments. These research questions are investigated for two case study sites whose functioning has previously been discussed 
[13] in relation to the 'No GRs' scenario (i.e. the current situation). This paper builds on the previously published materials and reports on further details of the water chemistry and the new results of calcicolous lichen surveying, which highlights the importance of the terrestrial habitat provided by engineered structures. It provides a summary of the baseline conditions; ecological patterns and the current level of ecosystem services are compared with those which may potentially result from the introduction of different types of GRs. In particular, specific attention is devoted to the indirect effects resulting from complex interactions among hydrology, water chemistry and the characteristics of the biological community $[14,15]$.

\section{HYDROLOGY}

The maps of the Juniper Green and Oxgangs ponds catchments are presented in Figs. 1 and 2 respectively. They are located south-west of central Edinburgh within the urban environment and about $4 \mathrm{~km}$ apart. As can be seen in these figures, the area covered by buildings appears to be relatively larger in the Juniper Green Catchment (35.5\%) than in the Oxgangs catchment $(25.6 \%)$. The coverage of other impermeable areas (e.g. pavements) is similar $(59.7 \%$ and $61.1 \%$ at Juniper Green and Oxgangs respectively), whilst there is considerably more green space at Oxgangs (13.3\%) compared to Juniper Green (4.8\%).

It should be noted that the catchment boundaries depicted in Figs. 1 and 2 (and subsequently used for the analysis) were first delineated using LIDAR data and then adjusted in line with the drainage schemes obtained from Scottish Water. The latter information helped to allocate the specific buildings, and even their parts, to the ponds' catchments. For example, according the Scottish Water drainage plans, runoff from the community centre located immediately west of the Oxgangs pond does not drain to the pond (Fig. 2). Also, there is a long building at

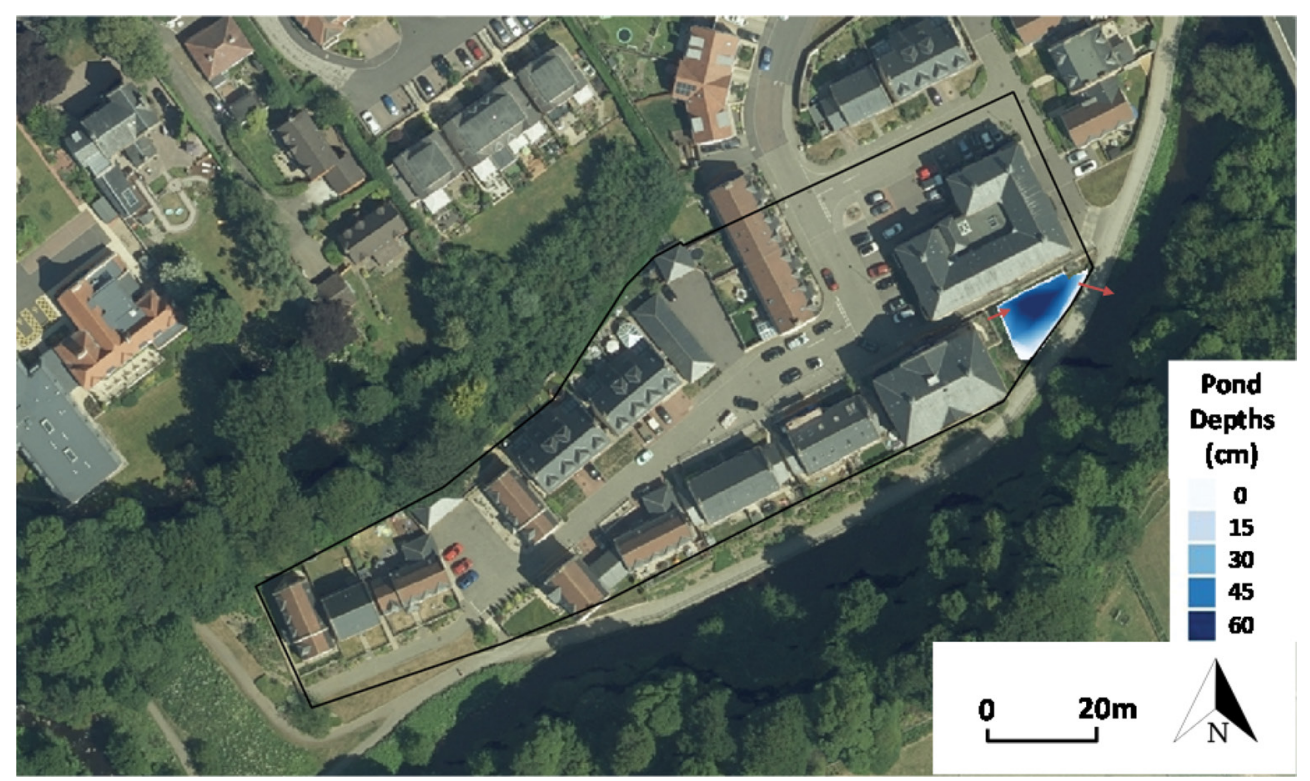

Figure 1: Catchment of the Juniper Green pond. The surface area of the pond is $220 \mathrm{~m}^{2}$. The inlet to the pond and outlet from the pond are shown as red arrows. The black line shows the catchment boundary for water that drains into the pond which has an area of $7,900 \mathrm{~m}^{2}$. 


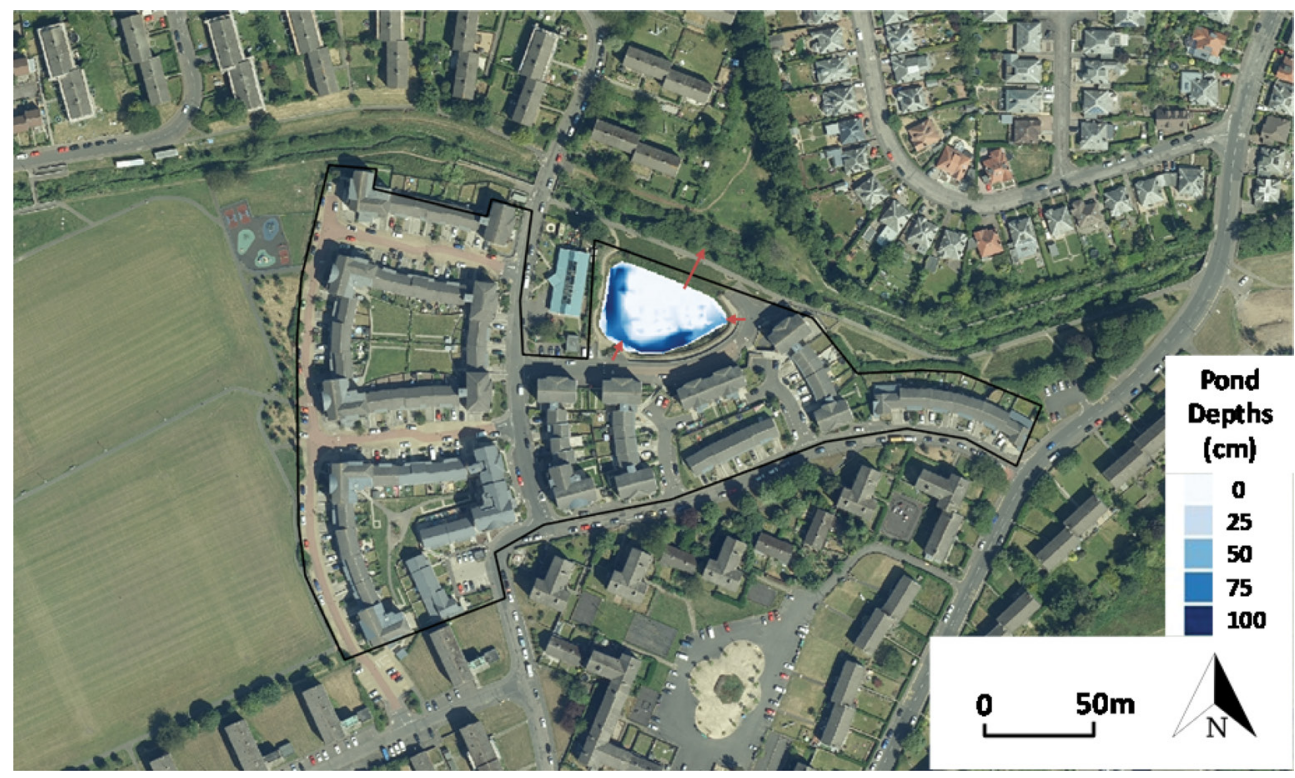

Figure 2: Catchment of the Oxgangs pond. The surface area of the pond is $1,750 \mathrm{~m}^{2}$. The two inlets to the pond and outlet from the pond are shown as red arrows. The black line shows the catchment boundary for water that drains into the pond which has an area of $30,800 \mathrm{~m}^{2}$.

the north of the Juniper Green catchment which only partly drains to the pond (Fig. 1); runoff from houses numbered 12-14 drains to the pond, whilst runoff from the house numbered 11 is diverted for drainage elsewhere.

Hydrological modelling of the ponds' catchments was carried out using SHETRAN, whilst hydrodynamic simulations of extreme events were performed using CityCAT. Both are wellestablished modelling analysis tools developed by Newcastle University [16-19]. For simulations involving green roofs scenarios, both models were adapted by adding a green layer over the areas covered by buildings. Two scenarios were considered: one with a 10-cm deep soil and one with a 20-cm deep soil. As CityCAT only considers events this is a simple storage term. In SHETRAN, parameters related to soil conductivity and evapotranspiration were adjusted to reproduce a slow release of water from saturated green roofs, following an exponential decay curve and decreasing to negligible values over 10 days. We also assumed a $10 \%$ residual water content which is not available for drainage from a green roof but is subject to gradual evaporation. This is a conservative estimate reflecting the uncertainty of slope and construction details. Further details on the catchments' properties and description of the software used are documented in our previous publication [13].

\subsection{Pond discharge and water residence times}

Figure 3 presents the estimated water discharges from both ponds under a range of scenarios. It is evident that although the retrofitting of GRs would result in the attenuation of discharge the differences between different scenarios are rather small. It should be noted, however, that these results are for daily discharge, and the instantaneous differences are expected to 


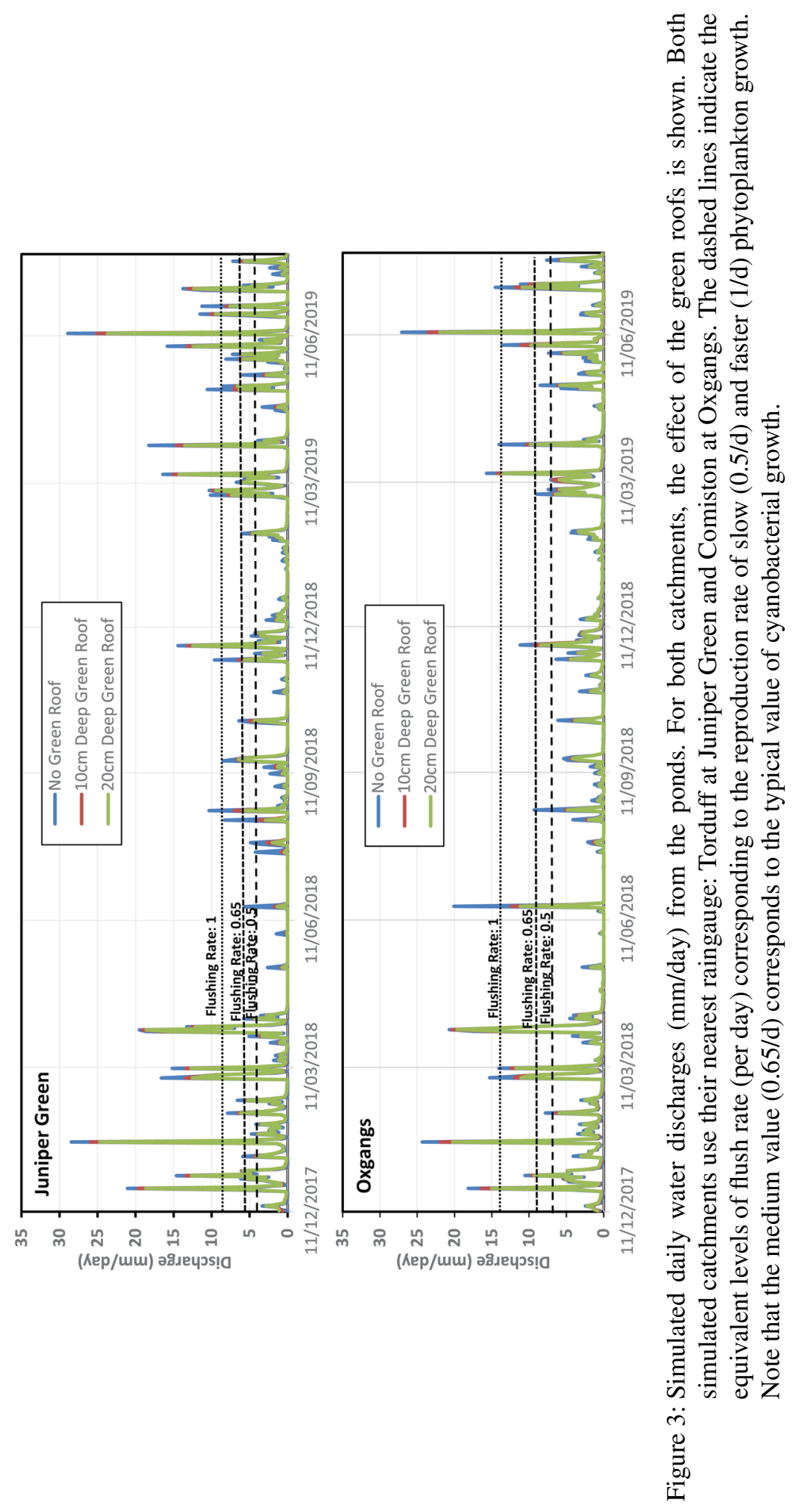


be more pronounced. It is also worth pointing out that the antecedent conditions strongly influence the magnitude of discharge resulting from specific precipitation events. In some cases, the green roofs would be saturated at the start of an event, whereas in other cases (e.g. 19.6.2018) the antecedent conditions would have made the soils drier so the roofs have a bigger effect. Another interesting point is that the patterns of reduction in discharge simulated by SHETRAN appear to be broadly similar, and this similarity was further confirmed by forcing both simulations using the same precipitation data for both catchments. The detailed analysis (not shown) confirms the similarity of these patterns $\left(r^{2}=0.82\right)$ and reveals that these reductions are slightly higher in Juniper Green because of the greater proportion of its catchment occupied by buildings. Overall, the discharge in the 20-cm GRs scenario over 17 months simulation period is reduced by $10.6 \%$ and $13.4 \%$ at Oxgangs and Juniper Green, respectively. These values are far below some of the reductions in the runoff rates reported in the literature - see e.g. [20] and references therein. The achieved reductions in discharge are, therefore, likely to be greater than our estimates. Consequently, the estimates in the increase of pond water residence time and the decrease of flush rate (see below) should be viewed as conservative as well.

Table 1 gives estimated water residence time under the examined scenarios for both ponds. Following the retrofitting of GRs, higher increases in residence time would be expected for Juniper Green. However, the key pattern emerging from this analysis is that under the normal operating conditions changes in water residence time in both ponds are expected to be rather limited. Nevertheless, there are a number of instances when some remarkable decreases in the flushing rate happen during the key seasonal stages of phytoplankton development, including, e.g. those when the flush rate drops below the equivalent value for daily increase in the slow-growing phytoplankton (Fig. 3).

\subsection{Simulation of extreme events}

Figures $4 \mathrm{a}$ and $\mathrm{b}$ present the results of CityCAT simulations for 1:100 year events (i.e. 100 years return period) of four different durations at Juniper Green and Oxgangs respectively. The differences in discharges under the examined scenarios are rather substantial and in all cases the green roofs reduce the peak discharge. It should be noted, however, that CityCAT does not in this case account for the antecedent conditions, so the reduction in discharge simulated in the model is a best-case scenario with dry initial conditions.

Table 1: Pond nominal residence times (days) estimated using SHETRAN. For both locations the depth of the green roofs on the buildings is shown. Both simulated catchments use their nearest raingauge: Torduff at Juniper Green and Comiston at Oxgangs. In addition, Oxgangs has been simulated using the Torduff rainfall so that a direct comparison between Juniper Green and Oxgangs can be carried out.

\begin{tabular}{|c|c|c|c|c|c|c|c|c|c|}
\hline \multirow[t]{2}{*}{ Month } & \multicolumn{3}{|c|}{$\begin{array}{l}\text { Juniper Green } \\
\text {-Torduff rainfall }\end{array}$} & \multicolumn{3}{|c|}{$\begin{array}{c}\text { Oxgangs - } \\
\text { Torduff rainfall }\end{array}$} & \multicolumn{3}{|c|}{$\begin{array}{c}\text { Oxgangs - } \\
\text { Comiston rainfall }\end{array}$} \\
\hline & $0 \mathrm{~cm}$ & $10 \mathrm{~cm}$ & $20 \mathrm{~cm}$ & $0 \mathrm{~cm}$ & $10 \mathrm{~cm}$ & $20 \mathrm{~cm}$ & $0 \mathrm{~cm}$ & $10 \mathrm{~cm}$ & $20 \mathrm{~cm}$ \\
\hline Apr18-Jun18 & 8.5 & 9.5 & 9.8 & 16.5 & 17.2 & 17.5 & 12.0 & 13.4 & 13.8 \\
\hline Jul18-Sept18 & 9.6 & 13.9 & 15.7 & 21.0 & 32.6 & 35.1 & 24.8 & 36.7 & 38.8 \\
\hline Oct18-Dec18 & 7.6 & 8.8 & 9.0 & 14.0 & 15.6 & 15.9 & 14.0 & 15.6 & 15.8 \\
\hline Apr19-Jun19 & 3.9 & 4.6 & 4.7 & 7.7 & 8.8 & 9.2 & 9.7 & 11.2 & 11.5 \\
\hline
\end{tabular}



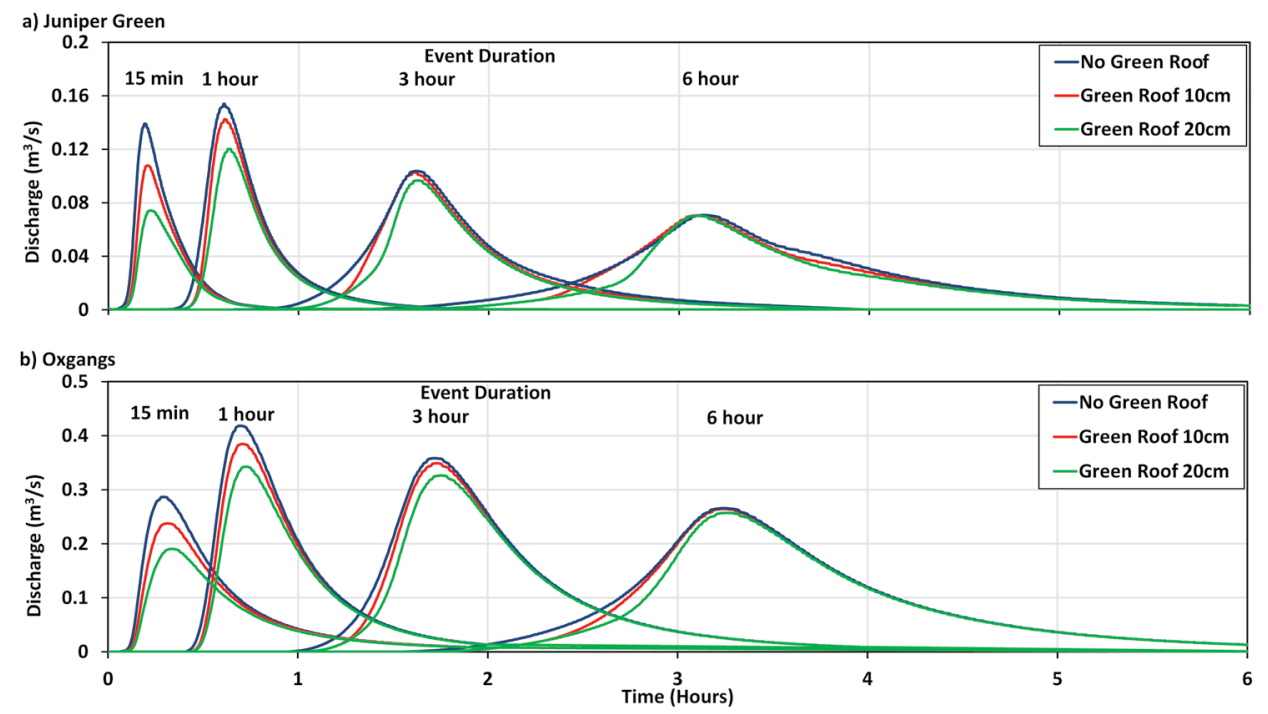

Figure 4: Simulated CityCAT discharges at (a) Juniper Green and (b) Oxgangs for 1:100 year events of four different durations with dry initial conditions.

The retrofitting of green roofs would have a greater effect for shorter duration events (e.g. $15 \mathrm{~min}-1 \mathrm{~h})$. For longer events $(6 \mathrm{~h})$, the effect of green roofs is bigger towards the start of the event and the effect on the peak discharge reduction is far less pronounced, as at this point during the event the green roofs become saturated and so unable to store any additional rainfall. It should also be noted that the introduction of green roofs would have a bigger effect on the peak discharge at Juniper Green for events of all durations. For the 15-min event, the reduction in peak discharge is $47.5 \%$ compared to a $33.6 \%$ reduction at Oxgangs. This reflects the higher roof coverage in its catchment.

\section{WATER CHEMISTRY}

Summary of the ICP analysis results for the monitored concentrations of selected chemicals are given in Fig. 5. As previously reported [13], Juniper Green water has lower electrical conductivity and lower total values of dissolved solids, which relates to its smaller and less diverse catchment in comparison with Oxgangs. This tallies well for comparison of concentrations of $\mathrm{B}, \mathrm{Ba}, \mathrm{Ca}, \mathrm{Mg}, \mathrm{Na}, \mathrm{Se}, \mathrm{Sr}, \mathrm{U}$ and Eu, which are all significantly lower in Juniper Green water samples. Furthermore, the levels of K, Li, P, Rb, Sb, Se, Si and Lu in Oxgangs also rather substantially exceed those in Juniper Green, and although the differences for these elements were previously reported as not statistically significant (using multcompare.m Matlab script on the dataset comprising results for 9 urban ponds), the explicit comparison of the Oxgangs and Juniper Green data using the Kruskal-Wallis (KW) test revealed significant differences for these elements (Fig. 5). Somewhat lower values in Juniper Green were also noted for Tm. In fact, the values of B (data not shown) - the element known to affect macroinvertebrate community - were only detectable in Juniper Green pond water in July 2018, when they ranged between 11 and $15 \mathrm{ppb}$. In contrast, the majority of B analysis for Oxgangs were above the detection limit of $10 \mathrm{ppb}$, and some were as high as $50 \mathrm{ppb}$. 


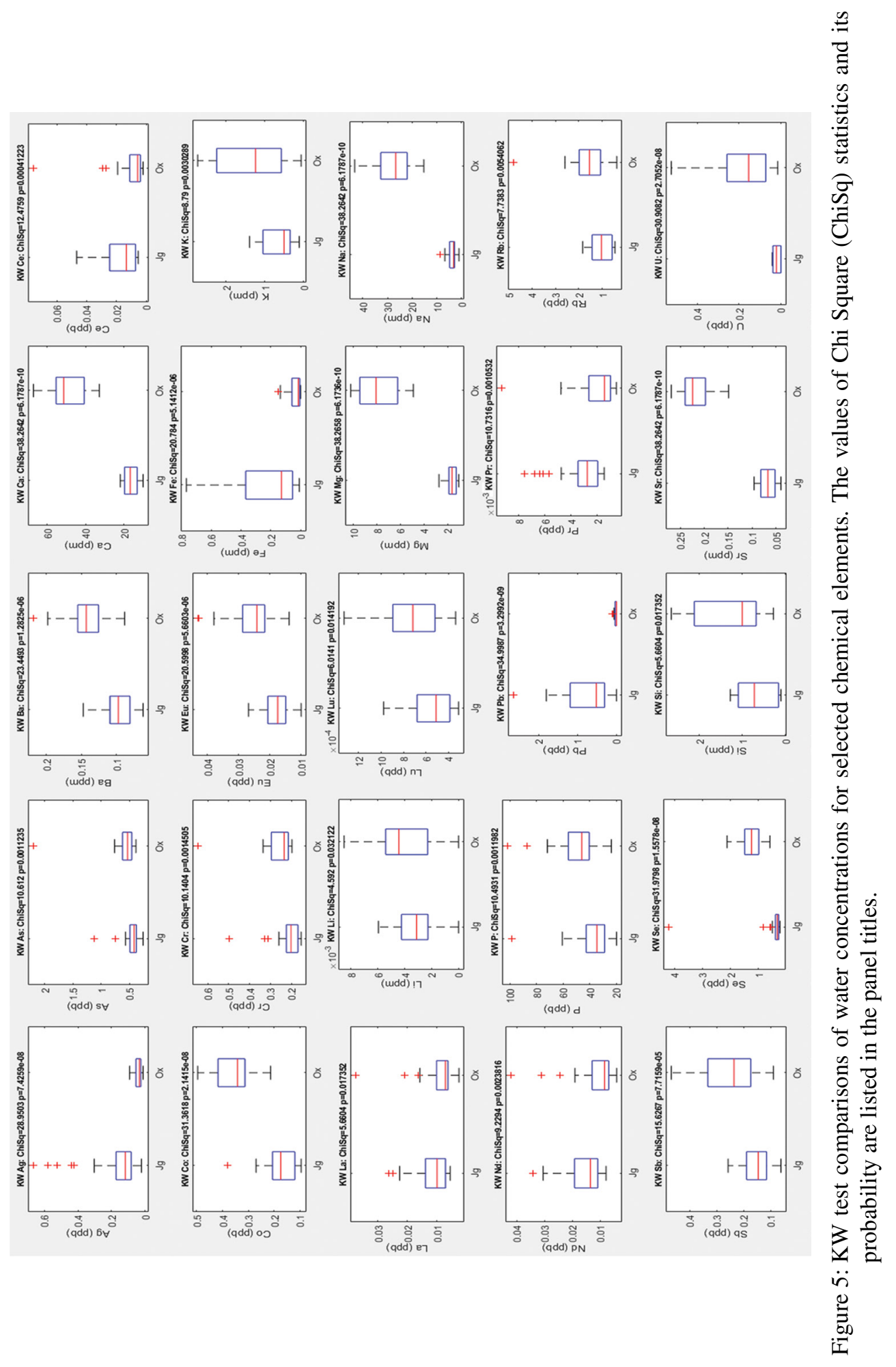


It should be noted, however, that the concentrations of $\mathrm{Pb}$ and $\mathrm{Ag}$ were significantly lower at Oxgangs. Iron levels were also notably lower in Oxgangs, and although the previous analysis (using multcompare.m Matlab script on the dataset comprising results for 9 urban ponds) did not find a significant difference owing to the overlapping ranges, the explicit comparison of the Oxgangs and Juniper Green data using the KW test revealed significant differences (Fig. 5). Further significant differences were also obtained for $\mathrm{La}, \mathrm{Ce}, \mathrm{Pr}$ and $\mathrm{Nd}$, which all appeared to be somewhat lower at Oxgangs. In addition, the values for $\mathrm{Tb}, \mathrm{Dy}, \mathrm{Zn}$ were somewhat lower in Oxgangs. It should also be noted that a previous study on suspended particles in Edinburgh ponds reported the presence of $\mathrm{Au}, \mathrm{Y}$ and Ir at Juniper Green, and that was attributed using factor analysis to the effect of discarded electronics. It is therefore likely that the enrichment of Juniper Green water in $\mathrm{Ag}, \mathrm{Pb}, \mathrm{Zn}$ and some rare earth elements (REE) may, in part, have also resulted from discarded electronics. An observation of a very high outlier value for water concentrations of $\mathrm{Ni}$ (well over $200 \mathrm{ppb}$, data not shown) also tallies well with this explanation.

\subsection{Potential Changes due to GRs}

Whilst for many chemical elements there is no information on their potential levels in GRs' runoff, it is expected that, in general, the introduction of GRs would lead to substantial increases in both suspended and dissolved solids. Consequently, elemental levels in the receiving stormwater ponds would be expected to rise as well. The exact magnitude of these changes is uncertain and would depend on the specifications of the roofs' construction and the details of technology used. Of primary importance would be characteristics of the substrate. Currently, it is recommended that the substrate mix for GRs should include substantial amount of concrete [21]. Consequently, following the retrofitting of GRs we may expect substantial increases in runoff concentrations of $\mathrm{Ca}, \mathrm{Si}, \mathrm{Al}$ and $\mathrm{Fe}$, which are the main elements comprising this material. There are also a number of admixtures variously used in concrete, including, e.g. sodium nitrate and calcium chloride. Such elements as, e.g. K, Ti, $\mathrm{Mg}$ and Mn may also be present in substantial amounts [22]. It should also be noted that GRs' substrates are specifically manufactured to promote plant growth, and may, therefore, be expected to have elevated concentrations of nutrients in their runoff.

A study in Canada reported that $\mathrm{P}, \mathrm{Al}$ and $\mathrm{Fe}$ may be considerably increased in GRs runoff [20]. Increases in the concentrations of $\mathrm{Mg}, \mathrm{Ca}, \mathrm{S}, \mathrm{Cl}$ and $\mathrm{Na}$ in GRs runoff (in comparison with conventional roofs) were also noted in that study, as well as increases in the detectability of such potentially problematic pollutants as $\mathrm{Pb}, \mathrm{Ni}, \mathrm{Cd}, \mathrm{Mo}, \mathrm{V}$ and $\mathrm{Be}$ (although it was noted that the levels were below statutory limits). However, the same study also found that many chemical variables had lower values in GRs runoff than in the runoff from conventional roofs. In particular, the runoff from conventional roofs had higher levels of $\mathrm{Zn}, \mathrm{Cu}, \mathrm{Mn}$ and polycyclic aromatic hydrocarbons (PAH). Furthermore, despite higher concentrations, the loads from GRs were lower for most chemicals due to lower runoff volumes.

Another study in Sweden [23] found that GRs appear to decrease the levels of Cd, and are very efficient in removing $\mathrm{N}$ from rain water; however, their runoff maybe enriched in $\mathrm{Ni}, \mathrm{Zn}$ and especially in $\mathrm{Cu}, \mathrm{P}, \mathrm{K}$, and DOC. Research in China [24] reported that runoff from GRs had lower $\mathrm{pH}$ than runoff from other roof types. The levels of electrical conductivity, total nitrogen, total organic carbon, $\mathrm{COD}, \mathrm{Cl}, \mathrm{K}, \mathrm{Na}, \mathrm{Ca}, \mathrm{Mg}, \mathrm{Cu}$ and $\mathrm{Si}$ were increased, whilst the concentrations of $\mathrm{P}$ and $\mathrm{F}$ were unaffected. 
A potential of GRs to increase runoff $\mathrm{pH}$ was also highlighted by a study in Singapore [25]. That could be beneficial for neutralising the effects of acid deposition. However, the runoff $\mathrm{pH}$ does not appear to be a problem for our ponds. The same study considered a comprehensive number of chemicals and highlighted the elevated levels of phosphates and nitrates in GRs runoff. The runoff also included significant amounts of $\mathrm{Na}, \mathrm{K}, \mathrm{Ca}, \mathrm{Mg}, \mathrm{Li}, \mathrm{Fe}$, $\mathrm{Al}$ and sulphates, and the variability in the monitored chemicals was influenced by the characteristics of substrates and the details of precipitation patterns. However, such potentially important pollutants as $\mathrm{Pb}, \mathrm{Cd}, \mathrm{Cr}, \mathrm{Co}$ and $\mathrm{Mn}$ did not appear in significant quantities [25].

In summary, although the exact changes are uncertain, there is a risk of water quality deterioration. Detailed considerations of interactions between chemistry and hydrology are indispensable for the correct assessment of the elemental budgets [26, 27] and further studies are needed. Furthermore, pollutants are readily adsorbed to suspended particulate matter (SPM). The dynamics of SPM in aquatic ecosystems is complex [28-31], and further research is required in that respect as well.

\section{HYDROBIOLOGY}

This section documents the differences and similarities between the current hydrobiological communities of Oxgangs and Juniper Green ponds. The potential changes to the community structure and patterns of ecological interactions are addressed in the discussion.

\subsection{Plankton}

There are a number of notable similarities and differences between planktonic community dynamics and composition at two ponds. In particular, it is worth pointing out the following features.

Firstly, the phytoplankton community at Oxgangs appears to be characterised by spring and autumn diatom blooms, with such genera as, e.g. Synedra, Cocconeis and Epithemia all frequently encountered [13]. The end of the spring maximum may be caused by a combination of factors related to grazing, hydraulics, and nutrient availability, and appears to be followed by a phytoplankton minimum in early Summer. Diatoms (including e.g. Synedra and Epithemia) are also encountered in Juniper Green, but less regularly and their planktonic forms have not been observed in blooming quantities. The clear water phase at Juniper Green was registered at the end of winter, and the responsible factors are likely to include low light and temperature, as well as high wash out rate due to the higher precipitation.

Secondly, the phytoplankton community at Juniper Green appears to be dominated by Spirogyra and (to a lesser extent) Peridinium. These taxa also occur in Oxgangs, but far less regularly and mostly in lesser quantities, although Spirogyra was prominent in July 2018 and May 2019 samples [13]. Mougeotia, on the other hand, at times becomes abundant at Oxgangs, whilst its occurrence in Juniper Green is much less prominent.

Thirdly, the cyanobacteria are encountered in both ponds, and usually in higher density in Summer and Autumn. Overall, however, they are more common in Oxgangs. Furthermore, in Juniper Green Microcystis is encountered much more often than Oscillatoria, whilst the opposite is true for Oxgangs where Microcystis is very rare.

Fourthly, although both ponds have Cyclops, Daphnia and Chydorus, such representatives of zooplankton community as Diaptomus were only encountered at Juniper Green. Furthermore, although a number of rotifer species were encountered at both ponds, the only regularly sampled species was Keratella quadrata, and only in Juniper Green. 


\subsection{Meiofauna}

Currently, the macroinvertebrate community in both ponds is mainly comprised of animals which are able to tolerate a wide range of conditions, including, e.g. Radix balthica and Asselus aquaticus, as well as representatives of Corixidae, Chironomidae, Coenagrionidae and Planorbidae. In both ponds there are also representatives of animals characteristic of medium quality conditions, e.g. Limnephilidae. Macroinvertebrate indices ASPT and WHPT indicate that biological water quality is better at Juniper Green [13], and that tallies well both with the water chemistry data discussed above, and the fact that Phryganeidae (another indicator of medium quality conditions) are found in Juniper Green only.

It should also be noted that there are notable differences in the community structure. The insect predators in Oxgangs are rare, whilst the predatory Chaoborus larvae (absent from Oxgangs) and hemipterans Notonecta glauca (rare in Oxgangs) are common in Juniper Green. The scarcity of insect predators in Oxgangs has been attributed to the presence of Gasterosteus aculeatus. These fish are absent from Juniper Green, which is a prerequisite for the population of palmate newts Lissotriton helveticus thriving at that site despite a very limited terrestrial habitat, which is also important for these animals. It should be noted that a single palmate newt female was previously recorded in Oxgangs by the NatureScot research team (David O'Brien, personal communication). However, neither their extensive search nor our sampling produced any evidence of other adults, juveniles or eggs. Hence there is no evidence of successful breeding of the newts there, and the Oxgangs pond site maybe acting as a sink for their population.

\section{BIODIVERSITY OF PLANTS AND FUNGI}

As has previously been documented [13], both case study sites are characterised by substantial species richness. Owing to its bigger size, there are many more vascular plants recorded at Oxgangs than at Juniper Green (103 vs 22, see Tables 2 and 3). The numbers of bryophytes, however, are less different (22 vs 16), and Juniper Green was shown to host a rare species Phaeoceros laevis [13]. The majority of vascular plants at Oxgangs are herbaceous (60 species) whilst there are 16 species within the 'trees/shrubs' category. This pattern also holds at the Juniper Green site (15 species of herbaceous plants, and 6 species within the 'trees/shrubs' category). It is also of interest to note that the majority of vascular plants at Oxgangs are native, and only 17 species ( 8 trees/shrubs, 9 herbs) belong to the non-native category. At the Juniper Green site, however, this pattern is reversed for the 'trees and shrubs' category, with almost all (and potentially all) of them being planted introductions with which the area around the pond has been landscaped. The aquatic and mesic habitats at this site are dominated by native taxa though.

It should also be noted that in addition to the purely aquatic habitat specialists, both sites host many plant species characteristic of mesic and terrestrial habitats (there are only 9 and 6 purely aquatic specialists at the Oxgangs and Juniper Green sites, respectively). That is very relevant for understanding the full extent of contribution these sites make to the local habitat diversity and their functioning as wildlife corridors. Terrestrial biodiversity is often ignored in studies of urban ponds. However, the area immediately adjacent to the water body and the nearby green space provide a plethora of microhabitats suitable for species with a wide range of ecological preferences. This is evident not only for plants (Tables 2 and 3) but also for fungi, and the previous research has documented 4 and 11 taxa of epiphytic lichens, as well as 2 and 5 non-lichenised fungi at Juniper Green and Oxgangs respectively [13]. 
Table 2: Vascular plants recorded at Oxgangs pond (Source: Krivtsov et al, 2020 [13]). (T) indicates species occupies terrestrial habitat, $(\mathrm{M})$ indicates species occupies mesic habitat, (A) indicates species occupies aquatic habitat, (E) indicates epiphyte. * indicates species/cultivar is not native to UK.

\begin{tabular}{|c|c|c|}
\hline \multicolumn{3}{|l|}{ Trees and shrubs: } \\
\hline Acer pseudoplatanus $(\mathrm{T}) *$ & Ilex aquifolium $(\mathrm{T})$ & Rubus idaeus $(\mathrm{T})$ \\
\hline Berberis thunbergii $(\mathrm{T}) *$ & Prunus avium $(\mathrm{T})$ & Salix sp $(\mathrm{T})$ \\
\hline Betula pendula $(\mathrm{T})$ & Pyracantha sp $(\mathrm{T}) *$ & Sorbus aucuparia $(\mathrm{T})$ \\
\hline Buddleja davidii $(\mathrm{T}) *$ & Rosa sp (T) & Symphoricarpos albus $(\mathrm{T}) *$ \\
\hline Escallonia sp $(\mathrm{T}) *$ & Rosa rugosa $(\mathrm{T}) *$ & Weigela florida $(\mathrm{T}) *$ \\
\hline Hedera helix (T/E) & Rubus fruticosus agg (T) & \\
\hline \multicolumn{3}{|l|}{ Herbaceous plants: } \\
\hline Agrostis capillaris $(\mathrm{T})$ & Geranium robertianum $(\mathrm{T})$ & Potamogeton natans (A) \\
\hline Anthriscus sylvestris $(\mathrm{T})$ & Geum urbanum $(\mathrm{T})$ & Ranunculus flammula (A) \\
\hline Arrhenatherum elatius (T) & Glyceria maxima $(\mathrm{M})$ & Ranunculus lingua (A) \\
\hline Atriplex patula $(\mathrm{T})$ & Heracleum sphondylium $(\mathrm{T})$ & Ranunculus repens $(\mathrm{T})$ \\
\hline Aster sp $(\mathrm{T}) *$ & Holcus lanatus $(\mathrm{T})$ & Rorippa sp (A) \\
\hline Bellis perennis $(\mathrm{T})$ & Iris pseudacorus (A) & Rumex obtusifolius $(\mathrm{T})$ \\
\hline Bromus sp $(\mathrm{T})$ & Jacobaea vulgaris $(\mathrm{T})$ & Sagina apetala $(\mathrm{T})$ \\
\hline Calendula officinalis $(\mathrm{T}) *$ & Lapsana communis $(\mathrm{T})$ & Sagina procumbens $(\mathrm{T})$ \\
\hline Caltha palustris (M) & Lagarosiphon major (A)* & Sedum sp (T) \\
\hline Capsella bursa-pastoris (T) & Lemna minor $(\mathrm{A})$ & Senecio vulgaris $(\mathrm{T})$ \\
\hline Cardamine hirsuta $(\mathrm{T})$ & Lolium perenne $(\mathrm{T})$ & Sinapis arvensis $(\mathrm{T})$ \\
\hline Centaurea nigra $(\mathrm{T})$ & Lotus pedunculatus $(\mathrm{T})$ & (archaeophyte) \\
\hline Cerastium fontanum $(\mathrm{T})$ & Lycopus europaeus (M) & Sisymbrium officinale $(\mathrm{T})$ \\
\hline Ceratophyllum demersum & Matricaria discoidea $(\mathrm{T}) *$ & Sonchus asper $(\mathrm{T})$ \\
\hline$(\mathrm{A}) *$ & Mentha aquatica $(\mathrm{M})$ & Sonchus oleraceus $(\mathrm{T})$ \\
\hline Cirsium arvense $(\mathrm{T})$ & Menyanthes trifoliata (A) & Stellaria graminea $(\mathrm{T})$ \\
\hline Cirsium vulgare $(\mathrm{T})$ & Mimulus sp $(\mathrm{M}) *$ & Stellaria media $(\mathrm{T})$ \\
\hline Dactylis glomerata $(\mathrm{T})$ & Myosotis arvensis $(\mathrm{T})$ & Trifolium pratense $(\mathrm{T})$ \\
\hline Digitalis purpurea $(\mathrm{T})$ & Narcissus pseudonarcissus & Trifolium repens $(\mathrm{T})$ \\
\hline Dryopteris sp $(\mathrm{T})$ & $\operatorname{cv} .(\mathrm{T}) *$ & Tripleurospermum \\
\hline Epilobium hirsutum $(\mathrm{T})$ & Phalaris arundinacea $(\mathrm{M})$ & maritimum $(\mathrm{T})$ \\
\hline Epilobium sp $(\mathrm{T})$ & Plantago lanceolata $(\mathrm{T})$ & Taraxacum aggregate $(\mathrm{T})$ \\
\hline Equisetum arvense $(\mathrm{T})$ & Plantago major $(\mathrm{T})$ & Tussilago farfara $(\mathrm{T})$ \\
\hline Erysimum sp $(\mathrm{T})$ & Poа аппиа $(\mathrm{T})$ & Typha latifolia $(\mathrm{T})$ \\
\hline (archaeophyte) & Polygonum aviculare $(\mathrm{T})$ & Urtica dioica $(\mathrm{T})$ \\
\hline Festuca rubra $(\mathrm{T})$ & Polypodium sp (T/E) & Vicia hirsuta $(\mathrm{T})$ \\
\hline Foeniculum vulgare $(\mathrm{T}) *$ & & Vinca major $(\mathrm{T}) *$ \\
\hline Galium aparine $(\mathrm{T})$ & & \\
\hline
\end{tabular}


Table 3: Vascular plants recorded at Juniper Green pond (Source: Krivtsov et al, 2020; [13]). See the caption of Table 2 for explanation of notations.

\begin{tabular}{lll}
\hline Trees and shrubs: & & \\
\hline Cornus $s p(\mathrm{~T}) *$ & $\begin{array}{l}\text { Cotoneaster salicifolia }(\mathrm{T}) * \\
\text { Cotoneaster } \operatorname{sp}(\mathrm{T}) *\end{array}$ & $\begin{array}{l}\text { Picea } \operatorname{sp}(\mathrm{T}) \\
\text { Rosa } \operatorname{sp}(\mathrm{T})\end{array}$ \\
Cotoneaster horizontalis $(\mathrm{T}) *$ & & \\
\hline Herbaceous plants: & & \\
\hline Alisma plantago-aquatica $(\mathrm{M} / \mathrm{A})$ & Crassula sp $(\mathrm{A})$ likely * & Juncus articulatus $(\mathrm{T} / \mathrm{M})$ \\
Callitriche stagnalis $(\mathrm{M})$ & Equisetum arvense $(\mathrm{T})$ & Juncus effusus $(\mathrm{T} / \mathrm{M})$ \\
Caltha palustris $(\mathrm{M})$ & Festuca rubra $(\mathrm{T})$ & Nymphaea alba $(\mathrm{A})$ \\
Carex pendula $(\mathrm{T})$ & Hedera helix $(\mathrm{T} / \mathrm{E})$ & Phragmites australis $(\mathrm{A})$ \\
Carex pseudocyperus $(\mathrm{M})$ & Iris pseudoacorus $(\mathrm{A})$ & Ranunculus lingua $(\mathrm{A})$ \\
\hline
\end{tabular}

\subsection{Calcicolous Lichens}

It should be noted that the lichen community at the Oxgangs site benefits from the presence of a wall constructed using stones in rip-rap (this type of gabion basket is not available at Juniper Green). Specifically, the top of the stones in rip-rap contains a more or less acid-loving type of community including Caloplaca holocarpa, Porpidia crustulata, Rhizocarpon reductum, cf. Amandinea punctata and Trapelia coarctata. The stones on the side of the same rip-rap host a more nutrient-rich community including Caloplaca citrina s.l., Lecania erysibe, Lecanora campestris, Myriolecis (Lecanora) dispersa s.1., and Myriolecis (Lecanora) semipallida. The nutrient enrichment here possibly reflects the inputs of nutrients washed off from soil above it and (lower down) also from the urine of dogs and foxes.

Nutrient enrichment at Oxgangs is also evident on the brick paving, which at the time of fieldwork was partially covered in canine excrement. The lichen community here is comprised of Aspicilia contorta, Lecidella stigmatea, Myriolecis (Lecanora) albescens, Myriolecis (Lecanora) semipallida, Phaeophyscia orbicularis and Porina chlorotica. In contrast, the brick paving on the path above the Juniper Green pond appeared to host only Collema tenax and Xanthoria parietina.

The mortar between the bricks at Oxgangs hosts the species characteristic of base-rich communities, including Verrucaria species (medium grey thallus, black partially-erumpent fruits) and an unidentified green sorediate crust with margins of nearly-continuous areoles with brighter yellowish-green soredia (when damp). In comparison, the base-rich community at Juniper Green is much more diverse; in addition to mortar the site also features a couple of concrete sills, a type of habitat lacking at Oxgangs (where the base-rich community is associated only with mortar). Verrucaria species (the same species as found on mortar at Oxgangs characterised by thick medium grey thallus with partially - erumpent fruits) is thriving here. There are, however, a number of additional species, such as Caloplaca holocarpa, Myriolecis (Lecanora) albescens, Myriolecis (Lecanora) hagenii, Myriolecis (Lecanora) semipallida and Verrucaria nigrescens.

The walls at Juniper Green host Caloplaca citrina s.1., Myriolecis (Lecanora) albescens, Myriolecis (Lecanora) dispersa s.1., Myriolecis (Lecanora) semipallida, Verrucaria species 1 (no thallus apparent, partially-erumpent black fruits) and Verrucaria species 2 (pale greyish white thallus with small fruits). This community is broadly indicative of base-rich conditions, 
probably attributable to the composition of the bricks and mortar. Despite the very different setting, without the evidence of allochthonous nutrient enrichment from use by domestic and urban mammals, the substrates of the walls and mortar support a similar base-rich community to Oxgangs. Nutrient enrichment is almost entirely absent on the pebbles under the ornamental waterwheel (nutrient-poor community) where there are such species as Porpidia crustulata, Porpidia tuberculosa, Rhizocarpon reductum, Trapelia coarctata and Trapelia placodioides, with the nutrient-loving Lecania erysibe on pebbles adjacent to the wall.

All in all, 17 and 20 calcicolous lichen taxa have been recorded on artificial substrates at Oxgangs and Juniper Green sites, respectively, thus providing a considerable addition to the biodiversity of these sites. It should be also noted that this account of calcicolous taxa is not comprehensive, as during the survey in Jan 2021 significant parts of the stonework were covered in frost and snow. It is, however, apparent that the lichens of these SUDS ponds sites are heavily dominated by those typical of nutrient-enriched sites, including mortar, concrete and ground in terrestrial urban environments, and that the degree of this enrichment is higher at Oxgangs. However, both surveyed sites have some small areas of nutrient-poor rock surfaces, like the tops of stones in the rip-rap around Oxgangs or the undisturbed landscaping pebbles behind the fence at Juniper Green. In both of these areas, ruderal communities of relatively common taxa have developed, marked by the distinctive dark patches of Rhizocarpon reductum in particular, a good indicator for this community. The less-organized looking Porpidia crustulata, with black apothecia scattered unpredictably across the thallus, is also relatively common, with a paler, more even texture.

\section{DISCUSSION AND CONCLUDING REMARKS}

The basic details of hydrology, ecology and multiple benefits provided by Oxgangs and Juniper Green ponds have been published before [13]. This paper has provided further information and a comparative summary describing ecological functioning, biodiversity, water chemistry and provision of ecosystem services by these case study SuDS ponds. The manuscript also gives an analysis of potential changes expected following the hypothetical retrofitting of GRs in the ponds' catchments.

There is unequivocal evidence that both SuDS ponds provide valuable multiple benefits related to the enhancement of local biodiversity, water quality improvement and alleviation of flood risk, which is in line with studies on other urban ponds [32, 33]. There is also a strong evidence that the retrofitting of GRs would further enhance flood resilience. It should also be noted that, based on studies elsewhere, the retrofitting of GRs is expected to increase the biodiversity of the area rather considerably. The retrofitting of GRs is unlikely to lead to any substantial changes in the floristic community associated with the ponds' study sites, although there might be some increase in species preferring stagnant conditions (e.g. Callitriche stagnalis). The terrestrial habitats would not be affected. It should be noted, however, that there may be potentially negative effects on the runoff water quality and biological community composition at the receiving SuDS ponds.

The observations on water chemistry summarised above implicate the impact of polluted runoff on both ponds. The magnitude of this impact, however, appears to be substantially greater for Oxgangs. There is also observational evidence (further confirmed through informal reports by local residents) that both ponds are affected by illegal disposal of discarded household items. This is particularly evident for Juniper Green, where a number of chemical signatures appear to originate from discarded electronic equipment. Overall, however, this pond is relatively oligotrophic. 
The retrofitting of GRs may increase the ponds' water residence time and the overall amount of dissolved substances, including nutrients and a range of pollutants. The exact changes in the pollutant loads are uncertain, but for many elements the pond water concentrations are likely to increase. The increase in hardness, however, is likely to be beneficial for reducing toxicity of metals. Nevertheless, the combined effect of these changes may disturb the current balance in the ponds' ecosystems and lead to the changes in their hydrobiological communities. The bottom-up effects are likely to propagate to the upper trophic levels and affect the current patterns of ecological relationships involving plankton and meiofauna. The level of these risks are higher for Juniper Green, as it is a very small pond with relatively low concentrations of dissolved chemicals.

It is also noteworthy that the retrofitting of GRs would result in more high flow events being reduced towards and even below the 0.65 equivalent value of flush rate (corresponding to the usual daily increase in cyanobacteria). However, greater residence time at Oxgangs combined with further increase in its trophic status would also bring about a concern for the potential increase in the occurrence of cyanobacteria capable of producing neuro- and hepato-toxins [34]. Interactions among ecosystem components are complex [35-42]. Consideration of indirect effects is paramount for the correct understanding of the functioning of ecological and environmental systems [15], and our analysis highlights that. The present study is, therefore, relevant to the development of comparative theoretical ecosystem analysis (CTEA), and further research and any potential management actions would benefit from the application of the CTEA methodological framework specifically designed to study indirect effects [14].

It is worth emphasising that the research presented here highlights the positive synergistic effects resulting from a combined application of two types of BGI installations (SuDS ponds and GRs). In addition, our study also objectively considers potential trade-offs related to the water quality and ecological community composition. This is relevant to the framework of NBS, and in particular such GIS-based assessment tools as NCPT and NGPT [43-45], aiming to account for the combined changes in ecosystem services and the resulting gain in natural capital. Thus although the prospective of complete retrofitting of GRs in the case study catchments considered here may seem unrealistic due to the logistical and financial reasons (especially given that typically the roofs are of the pitched kind), this research, nevertheless, will be of use for practitioners planning new developments where the application of GRs and SuDS ponds is considered either simultaneously or as alternatives (such as, e.g. Meadowbank development in Edinburgh [46]). More generally, the CTEA methodology and the analysis presented here will be of value for any considerations of complex NBS alternatives, and is therefore relevant to the ongoing development of the BGC/Sponge Cities conceptual framework $[2,3,47-51]$.

\section{ACKNOWLEDGEMENTS}

David Chamberlain, Adrian Sumner, Derek Christie, Janee Lomax, Alejandro Sevilla, Alice Masip, Achiraya Kraiphet, Yamina Monteiro, Simon Kennedy, Cameron Diekonigin, Heather Forbes, Caroline Cruickshank and Cesare Pertusi are kindly thanked for their various contributions to fieldwork, data processing and identification/biological recording. Heather Forbes also made a valuable contribution to proofreading and formatting the manuscript, and preparing the vegetation tables. Help of Garth Foster was invaluable in identifying water beetles. David O'Brien is thanked for providing valuable comments, and the information on his team's sampling at Oxgangs. The analysis presented in this paper builds on the previously 
published work [13], which was, in part, supported by the UFR project funding (EPSRC grant nos. EP/P004180/1, EP/P004334/1 and EP/P003982/1). Preparation of this manuscript was, in part, supported by the RBGE core funding.

\section{REFERENCES}

[1] D’Arcy BJ, Kim L-H, Maniquiz-Redillas M., Wealth creation without pollution. Designing for industry, ecobusiness parks and industrial estates. London: IWAP; 2018.

[2] O'Donnell E, Thorne C, Ahilan S, Arthur S, Birkinshaw S, Butler D, et al. The blue-green path to urban flood resilience. Blue-Green Systems. 2020;2(1):28-45.

[3] Fenner R. Spatial evaluation of multiple benefits to encourage multi-functional design of sustainable drainage in blue-green cities. Water. 2017;9(12):953.

[4] Fenner R, O’Donnell E, Ahilan S, Dawson D, Kapetas L, Krivtsov V, et al. Achieving urban flood resilience in an uncertain future. Water. 2019;11(5).

[5] Morgan M, Fenner R. Spatial evaluation of the multiple benefits of sustainable drainage systems. Proceedings of the Institution of Civil Engineers - Water Management 2019 2019;172(1):39-52.

[6] CIRIA. Blue-green infrastructure - perspectives on planning, evaluation and collaboration. London: CIRIA C780a; 2019.

[7] Oberndorfer E, Lundholm J, Bass B, Coffman RR, Doshi H, Dunnett N, et al. Green roofs as urban ecosystems: ecological structures, functions, and services. BioScience. 2007;57(10):823-33.

[8] Köhler M, Ksiazek-Mikenas K. Chapter 3.14 - Green Roofs as Habitats for Biodiversity. In: Pérez G, Perini K, editors. Nature Based Strategies for Urban and Building Sustainability: Butterworth-Heinemann; 2018. p. 239-49.

[9] Shafique M, Xue X, Luo X. An overview of carbon sequestration of green roofs in urban areas. Urban Forestry \& Urban Greening. 2020;47:126515.

[10] Ahilan S, Guan MF, Wright N, Sleigh A, Allen D, Arthur S, et al. Modelling the long-term suspended sedimentological effects on stormwater pond performance in an urban catchment. Journal of Hydrology. 2019;571:805-18.

[11] Jarvie J, Arthur S, Beevers L. Valuing multiple benefits, and the public perception of SUDS ponds. Water 2017;9(2):128.

[12] O'Brien CD. Sustainable drainage system (SuDS) ponds in Inverness, UK and the favourable conservation status of amphibians. Urban ecosystems. 2015;18(1):321-31.

[13] Krivtsov V, Birkinshaw S, Forbes H, Olive V, Chamberlain D, Lomax J, et al. Hydrology, ecology and water chemistry of two suds ponds: detailed analysis of ecosystem services provided by blue-green infrastructure. WIT Transactions on The Built Environment. 2020;194:167-78.

[14] Krivtsov V. Investigations of indirect relationships in ecology and environmental sciences: a review and the implications for comparative theoretical ecosystem analysis. Ecological Modelling. 2004;174(1-2):37-54.

[15] Krivtsov V. Indirect Effects in Ecology. In: Jorgensen SE, Fath BD, editors. Encyclopedia of ecology: Newnes; 2008. p. 1948-58.

[16] Ewen J, Parkin G, O'Connell PE. SHETRAN: distributed river basin flow and transport modeling system. Journal of hydrologic engineering. 2000;5(3):250-8.

[17] Lewis E, Birkinshaw S, Kilsby C, Fowler HJ. Development of a system for automated setup of a physically-based, spatially-distributed hydrological model for catchments in Great Britain. Environmental Modelling \& Software. 2018;108:102-10. 
[18] Glenis V, Kutija V, Kilsby CG. A fully hydrodynamic urban flood modelling system representing buildings, green space and interventions. Environmental Modelling \& Software. 2018;109:272-92.

[19] Birkinshaw SJ, O'Donnell G, Glenis V, Kilsby C. Improved hydrological modelling of urban catchments using runoff coefficients. Journal of Hydrology. 2021;594:125884.

[20] Van Seters T, Rocha L, Smith D, MacMillan G. Evaluation of green roofs for runoff retention, runoff quality, and leachability. Water Quality Research Journal. 2009;44(1):33-47.

[21] Gedge D, Grant G, Kadas G, Dinham C. Creating green roofs for invertebrates - a best practice guide. Peterborough: Buglife; 2012.

[22] Ibrahim MW, Hamzah AF, Jamaluddin N, Ramadhansyah P, Fadzil A. Split tensile strength on self-compacting concrete containing coal bottom ash. Procedia-Social and Behavioral Sciences. 2015;195:2280-9.

[23] Ahmed N. Runoff water quality from a green roof and in an open storm water system. TVVR 10/5020. 2011.

[24] Zhang Q, Wang X, Hou P, Wan W, Li R, Ren Y, et al. Quality and seasonal variation of rainwater harvested from concrete, asphalt, ceramic tile and green roofs in Chongqing, China. Journal of Environmental Management. 2014;132:178-87.

[25] Vijayaraghavan K, Joshi UM, Balasubramanian R. A field study to evaluate runoff quality from green roofs. Water Research. 2012;46(4):1337-45.

[26] Krivtsov V, Bellinger E, Sigee D. Water and nutrient budgeting of Rostherne Mere, Cheshire, UK. Nordic Hydrology. 2002;33(5):391-414.

[27] CIRIA. Blue-green infrastructure - perspectives on water quality benefits. London: CIRIA C780b; 2019.

[28] Ahilan S, Guan M, Wright N, Sleigh A, Allen D, Arthur S, et al. Modelling the longterm suspended sedimentological effects on stormwater pond performance in an urban catchment. Journal of hydrology. 2019;571:805-18.

[29] Krivtsov V, Howarth M, Jones S. Characterising observed patterns of suspended particulate matter and relationships with oceanographic and meteorological variables: studies in Liverpool Bay. Environmental Modelling \& Software. 2009;24(6):677-85.

[30] Krivtsov V, Howarth M, Jones S, Souza A, Jago C. Monitoring and modelling of the Irish Sea and Liverpool Bay: an overview and an SPM case study. Ecological Modelling. 2008;212(1-2):37-52.

[31] Krivtsov V, Arthur S, Buckman J, Kraiphet A, Needham T, Gu W, et al. Characterisation of suspended and sedimented particulate matter in blue-green infrastructure ponds. Blue-Green Systems. 2020;2(1):214-36.

[32] Krivtsov V, Arthur S, Buckman J, Bischoff J, Christie D, Birkinshaw S, et al. Monitoring and Modelling SUDS Retention Ponds: Case Studies from Scotland ICONHIC; Chania, Greece. http://www.urbanfloodresilience.ac.uk/documents/krivtsov-et-al.-iconhic-2019b. pdf 2019.

[33] Krivtsov V, Birkinshaw S, Arthur S, Knott D, Monfries R, Wilson K, et al. Flood resilience, amenity and biodiversity benefits of an historic urban pond. Philosophical Transactions of the Royal Society A. 2020;378(2168):20190389.

[34] Codd G. Toxins of freshwater cyanobacteria. Microbiological Sciences. 1984;1(2):48-52.

[35] Krivtsov V, Tien C, Sigee D, Bellinger E. X-ray microanalytical study of the protozoan Ceratium hirundinella from Rostherne Mere (Cheshire, UK): dynamics of intracellular elemental concentrations, correlations and implications for overall ecosystem functioning. Netherlands Journal of Zoology. 1999;49(4):263-74. 
[36] Bloor MC, Banks CJ, Krivtsov V. Acute and sublethal toxicity tests to monitor the impact of leachate on an aquatic environment. Environment International. 2005;31(2):269-73.

[37] Bloor MC, Banks CJ, Krivtsov V. Population dynamics in Asellus aquaticus as modified by chronic leachate stress. Engineering Geology. 2006;85(1-2):9-13.

[38] Krivtsov V, Illian J, Liddell K, Garside A, Bezginova T, Salmond R, et al. Some aspects of complex interactions involving soil mesofauna: analysis of the results from a Scottish woodland. Ecological Modelling. 2003;170(2-3):441-52.

[39] Krivtsov V. Study of cause-and-effect relationships in the formation of biocenoses: their use for the control of eutrophication. Russian Journal of Ecology. 2001;32(4):230-4.

[40] Krivtsov V, Bezginova T, Salmond R, Liddell K, Garside A, Thompson J, et al. Ecological interactions between fungi, other biota and forest litter composition in a unique Scottish woodland. Forestry. 2006;79(2):201-16.

[41] Tien CJ, Krivtsov V, Levado E, Sigee DC, White KN. Occurrence of cell-associated mucilage and soluble extracellular polysaccharides in Rostherne Mere and their possible significance. Hydrobiologia. 2002;485(1-3):245-52.

[42] Krivtsov V, Sigee DC. Importance of biological and abiotic factors for geochemical cycling in a freshwater eutrophic lake. Biogeochemistry. 2005;74(2):205-30.

[43] Puchol-Salort P, Van Reeuwijk M, Mijic A. Natural Capital Impact Assessment.

[44] Hölzinger O, Sadler J, Scott A, Grayson N. NCPT-managing environmental gains and losses. Town \& Country Planning. 2019:167.

[45] Ncube S, Arthur S, Kapetas L, Fenner R, Birkinshaw S. Impact of blue/green and grey infrastructure interventions on natural capital in urban development.

[46] Collective Architecture. Meadowbank development green roof options appraisal. Collective architecture; 2020.

[47] Grant G. Ecosystem services come to town: greening cities by working with nature: John Wiley \& Sons; 2012.

[48] Brears RC. Blue and Green Cities: the role of blue-green infrastructure in managing urban water resources: Springer; 2018.

[49] Lashford C, Rubinato M, Cai Y, Hou J, Abolfathi S, Coupe S, et al. SuDS \& sponge cities: a comparative analysis of the implementation of pluvial flood management in the UK and China. Sustainability. 2019;11(1):213.

[50] Krivtsov V, D’Arcy BJ, Sevilla AE, Arthur S, Semple C. Mitigating Polluted Runoff from Industrial Estates by SUDS Retrofits: Case Studies of Problems and Solutions Co-Designed with a Participatory Approach, Sustainability (In Press). 2021.

[51] Krivtsov V, Ahilan S, Arthur S, Birkinshaw S, Dawson D, Everett G, et al. Blue-Green Cities: Achieving Urban Flood Resilience, Water Security and Biodiversity. The Palgrave Encyclopedia of Urban and Regional Futures (in Press), ed. R.C. Brears, 2021. 